\title{
Computational Thinking Concepts for Grade School
}

John F. Sanford, Professor Emeritus, Philadelphia University, USA

Jaideep T. Naidu, Philadelphia University, USA

\begin{abstract}
Early education has classically introduced reading, writing, and mathematics. Recent literature discusses the importance of adding "computational thinking" as a core ability that every child must learn. The goal is to develop students by making them equally comfortable with computational thinking as they are with other core areas of early education. Computational thinking does not come naturally and requires training and guidance. This paper argues for the inclusion of computational thinking in tandem with mathematics. As an example, the paper demonstrates spreadsheet applications that can be utilized concurrently with early mathematical concepts. It demonstrates that at this time, spreadsheets are the best medium for inculcating computational thinking but recognizes that advances in technology may favor other digital approaches in time.
\end{abstract}

Keywords: Computational Thinking; Analytical Solutions; Spreadsheet Modeling; Grade Schools

\section{INTRODUCTION AND OVERVIEW}

\section{The Digital Age}

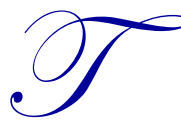

he last half a century witnessed something only dimly dreamed of in earlier times. The digital computer became a reality and with it a revolution perhaps more significant than the industrial revolution. Digital computation provides the ability to dramatically augment human thinking and understanding. It has produced an explosion of information. Knowledge workers who partner with digital computing machinery open new horizons of capability. Almost every avenue of science, engineering, and general business, employs digital computation. Such computation may involve extraction of knowledge from vast quantities of data, or mathematical solutions unavailable through other means. Another increasingly valuable approach to understanding natural phenomena has involved employment of mathematical models constructed with digital computers to simulate behavior of such phenomena. The salient feature of these efforts is that the human mind and the computer work together to find solutions or to pioneer new areas of science.

The popular term encompassing the use of digital computing as an aid to thinking and problem solving is "computational thinking" (http://www.cs.cmu.edu/ CompThink/). Today, technology appears at the earliest level of public education in the U.S. This paper points out a way in which this new technology can be employed as a ubiquitous partner to learning science and mathematics. An early introduction of "computational thinking" is required as such thinking is critical in today's world. Jeanette Wing (2006) states that computational thinking is a fundamental skill for everyone, not just for computer scientists. Computational thinking involves solving problems, designing systems, and understanding human behavior, by drawing on the concepts fundamental to computer science. Computational thinking is conceptualizing i.e., thinking at multiple levels of abstraction and it complements and combines mathematical and engineering thinking (Wing, 2006).

\section{The Education Process}

Classical education has always included literature, mathematics, sciences, and music. Literature and rhetoric enhance communication skills. Knowledge of mathematics enhances one's ability to think logically. Study of the sciences enhances one's understanding of the world and how it functions. It is said that early music training helps develop logical and reasoning skills. Computational thinking involves use of digital computers to augment problem 
solving and thought processes. It can and does augment, facilitate, and expand the realm of thinking, logic, and mathematics. Scientists and researchers in such diverse fields as biology, chemistry, physics, astronomy, medicine, and others, currently use digital computers for "mathematical modeling" to expand the frontiers of knowledge in ways that are definitely not available otherwise (Monroe, 2014). It becomes apparent that our "knowledge-based" world requires all of us to understand how to utilize computational technology even for everyday activities and certainly for productivity at the workplace.

Computational thinking concepts should be available to enrich daily life in modern society. Home owners need not be mystified by mortgage calculations. They should understand how to compare costs of alternative actions such as renting versus home purchase. Support for innumerable in-home tasks is available on personal computers and on the Internet. As an example, millions of Americans file their annual tax returns with the aid of computer applications available on the Internet.

\section{Occupational Requirements}

Employees in today's world must be able to communicate their ideas clearly and succinctly; to arrive at logical deductions; to recognize logical inferences; and to develop innovative ideas. Education of the young must support these goals. A few decades back, one would have found the typical sales clerk tallying up item prices and making changes manually. Now a digital machine does what the clerk's brain did in the past. With routine tasks automated, managers now concern themselves with more advanced concepts. What are traffic patterns within a store? What are customer preferences? How can individual customer preferences be ascertained so that these customers may be offered specific products that they are likely to purchase? Are certain items complementary and generally purchased together? What trends are observable? Answers are available but only to those who understand the resources available through data analysis.

Computers utilizing "artificial intelligence" have already been demonstrated (IBM, 2011). Computing power is increasing exponentially with time so one may expect that "computational thinking" defined in future years may be quite different from today's definition. However, humans need the ability to utilize technology as an enhancement of continually increasingly essential skills in science, mathematics, and logical thought.

\section{Teaching Computational Thinking}

How and when should computational thinking be introduced to students? There seems to be a consensus that the child needs to learn reading, writing, and arithmetic at an early age. Mental arithmetic builds the framework for mathematical logic and problem-solving. In their early years, children learn addition and subtraction, memorize the times table, learn division, and so on. Nothing in the classical approach to education has been obviated by new technology. Advantages of computational thinking are additive and do not interfere with the accepted fundamental aspects of a child's educational development. Computational thinking is an augmentation to problem solving and hence can be introduced when word problems are introduced. Mathematical word problems describe a situation and ask the student to form a mathematical solution. The solution really arises from what could be called a mathematical model. As an example, "If Fred has 6 apples and Jane has 3 apples, how many apples do Fred and Jane have together?" The assumption is that use of a calculator is not recommended because students should be able to perform elementary mental arithmetic. Similarly, electronic aids and computer solutions should be introduced only after the child has thoroughly mastered the mental arithmetic required for solutions to such simple problems.

The introduction of word problems should be followed by an introduction to digital mathematical modeling. This opens the door to a more thorough understanding of related solutions which may present themselves simply because calculation is automatic with the aid of a computer. The spontaneous development of other solutions engenders enthusiasm for innovation and experimentation which is a learning goal not thoroughly attained under current educational practices. What if Fred has only four apples? If Fred and Jane have 10 apples together, what combinations of ownerships are possible? Manual calculations of such combinations can be tedious and thus one would be less inclined to try them. A thorough study of any problem becomes easy with the aid of a computer and students can be encouraged to innovate and investigate other situations. 


\section{Digital Platforms}

The main argument of this paper is to provide technology as a natural extension of existing methods. At the present time, the most likely choice for introducing computer models to the young student is through spreadsheets. When properly executed, they produce a visual display very close to what would appear in a manual solution with the added advantage that such a display is also rectilinear and orderly. Spreadsheets are used extensively for business applications and clearly there is value in learning them at any age. They can be easily understood and come with features which encourage self-expression and experimentation. They also allow easy extensions and exploration of alternate approaches. They also offer iterative procedures to find solutions to some problems that are otherwise available only through advanced mathematical effort.

Platforms other than spreadsheets are available and could be introduced when appropriate for more complicated problems. Advanced applications can also be found as spreadsheet add-ins. An extensive library of computerized learning aids and even games that develop thinking skills already exists. Many computer scientists advocate teaching a computer language such as Python during elementary education. Sample lesson plans for teaching a computer language at the elementary level are already available on the Internet (Google, 2014). These however, do not have the ubiquitous appeal of spreadsheets.

There is one final injunction. "Computational thinking" should not be a separate course. Current literature suggests that digital computational learning should be presented in parallel with developing mathematical and science skills and applied where useful (Best, 2014) and (Wilensky, Brady and Horn, 2014). It is complementary to the other core skills a child develops in school. There is real value when a child is able to see that computational technology can be extended to solve similar problems, the different ways a solution can be presented and also develop the ability to ask "what if" questions. Students should be encouraged to expand a given problem and find new ways of looking at it. The goal is to encourage initiative and innovation.

We present several examples as an effort to precisely convey the ideas contained in this paper.

\section{ILLUSTRATIVE EXAMPLES}

\section{Problem 1}

Consider the word problem related to Dick and Jane mentioned earlier. Students will deal with some examples of such problems in the traditional fashion to develop confidence with each new concept. Eventually they should have an opportunity to investigate mathematical models on a spreadsheet. Here is one example which expands on an earlier paper by one of the authors (Sanford, 2013).

Juan has 3 apples. Shana has twice as many apples as Juan. Together how many apples do they have? Using algebra, let $\mathrm{J}$ equal the number of apples that Juan has and $\mathrm{S}$ equal the number of apples Shana has. $\mathrm{J}=3$ and $\mathrm{S}=2 \mathrm{x}$ $3=6 \rightarrow \mathrm{J}+\mathrm{S}=3+6=9$. This is easily transported to a spreadsheet as a template. Columns in a spreadsheet are identified by letters A, B, C, and so on. Rows are identified by numbers 1, 2, 3, and so on. Cells are designated by the columns and rows that define them, such as A1, B1, and so on.

Good form is as important to spreadsheets as it is to paper and pencil work. Figure 1 shows a spreadsheet with labels that reflect the problem. We have Juan and Shana. Here J is used for Juan and S for Shana. One column is labeled apples. Rows are labeled $J$ and $S$. It only remains to fill in the quantity of apples belonging to $J$ and to $S$. Figure $2 a$ shows how this can be done. The student writes " $=2 * \mathrm{~B} 3$ " in cell B4 as shown. When the "Enter" key is pressed, that cell will show the number 6 . Of course, the algebraic formula is " $=2 * \mathrm{~J}$ " but the computer understands the name B3 for the cell containing Juan's apple count. If this presents confusion for beginners at a young age, it is possible to tell the computer that it should use $\mathrm{J}$ for the cell name instead of B3. This is easy to do although the method differs among different spreadsheet software. Naming a cell can make the solution steps intuitive. Remember that in Figure 1 , the cell to the right of J represents Juan's apple count. We can name it the "J" cell. The cell containing the letter "I" is a label cell as no number is placed there. The cell to the right of $\mathrm{S}$ is named the "S" cell and represents Shana's apples. The figures show results using Excel 2010 but any spreadsheet will present similar capabilities. 
There are other products including Google Docs, Open Office, Lotus, etc. Figures for those products would be only superficially different.

Figure 1 Labels

\begin{tabular}{|c|c|c|}
\hline \multicolumn{1}{|c|}{} & A & \multicolumn{1}{|c|}{ B } \\
\hline 1 & J=Juan & S= Shana \\
\hline 2 & & apples \\
\hline 3 & J & \\
\hline 4 & S & \\
\hline 5 & & \\
\hline
\end{tabular}

Figure 2a Shana has $2 * \mathrm{~J}$ apples

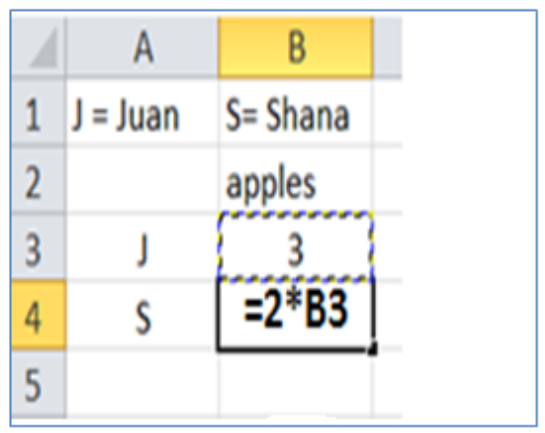

Figure $2 \mathrm{~b}$ Shana has $2 * \mathrm{~J}$ apples

\begin{tabular}{|c|c|c|}
\hline 4 & A & B \\
\hline 1 & $\mathrm{~J}=$ Juan & $\mathrm{S}=$ Shana \\
\hline 2 & & apples \\
\hline 3 & $\mathrm{~J}$ & 3 \\
\hline 4 & $\mathrm{~S}$ & $=2 * \mathrm{~J}$ \\
\hline 5 & & \\
\hline
\end{tabular}

Once cells are named, formulas may be written just as they would appear in algebraic form. The expression indicating that Shana has twice as many apples as Juan would be $\mathrm{S}=2 \mathrm{~J}$ as shown in Figure 2b. It looks like Figure 2a except that the name for cell B4 is used in place of its coordinates. The solution appears in the "S" cell (i.e. cell B4) when the Enter key is pressed. Cells A3 and A4 do not hold data and never used in calculations but supply labels when creating charts. Cells do not have to be named but the technique is useful even for advanced students. If the naming process is confusing for beginners, the spreadsheet may be set up in advance as a template by the instructor.

The next step would logically be to create a column label called "Sum" as shown in Figure 3. The cell below it (D2) will hold the sum quantity. As stated earlier, naming is only an option and could be used to maintain closeness to the algebraic method. The formula for the Sum is " $=\mathrm{J}+\mathrm{S}$ ". Upon pressing the Enter key, cell D2 will contain 9. This is a general solution in the sense that the number of apples for either party may be changed and the Sum will always reflect those changes.

\section{Figure 3 Sum $=\mathrm{J}+\mathrm{S}$ (caps not necessary)}

\begin{tabular}{|c|c|c|c|c|}
\hline \multicolumn{1}{|c|}{} & A & B & C & D \\
\hline 1 & J = Juan & S= Shana & & Sum \\
\hline 2 & & apples & & $=J+S$ \\
\hline 3 & J & 3 & & \\
\hline 4 & S & 6 & & \\
\hline
\end{tabular}

A Variation to this problem: Suppose the problem now states that there are a total of 12 apples. How many apples does Juan have if Shana still has twice as many apples as Juan? The algebraic solution is: $\mathrm{S}=2 \mathrm{~J} \rightarrow \mathrm{J}+2 \mathrm{~J}=12 \rightarrow 3 \mathrm{~J}$ $=12 \rightarrow \mathrm{J}=12 / 3=4$.

Spreadsheets have an app called "Goal Seek" that will search for an appropriate value for the J cell to make the sum equal to 12. The window for Goal Seek is shown in Figure 4. Goal Seek will recognize names if they have been used. In Excel 2010, the app is found on the "Data" tab at the top of the spreadsheet. Other information must be entered appropriately and Goal Seek finds the solution as shown in Figure 5. Goal Seek is not interactive because it must be "run" again if the desired sum changes. However, a spreadsheet solution is interactive and values are recalculated when the user makes data changes. The solution serves as a template for future solutions of similar problems. A student could be drilled by more variations. Suppose Shana now has 3 times the apples as Juan. What is the new sum? 


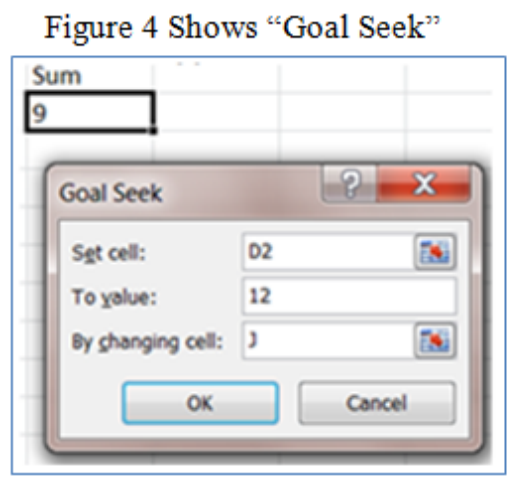

Figure 5 Goal Seek finds a value for J

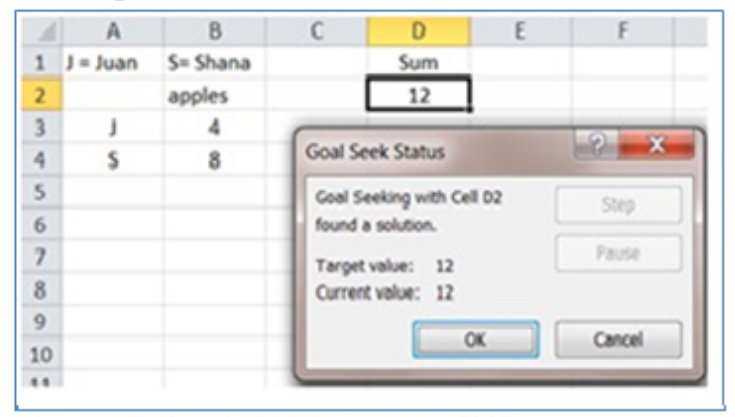

A word of caution for another Variation: The original problem could have been written as $\mathrm{J}=\mathrm{S} / 2$. This means, Juan has half as many apples as Shana? This is true but the $\mathrm{J}=\mathrm{S} / 2$ and $\mathrm{S}=2 \mathrm{~J}$ logic goes around in a circle. Solving these equations algebraically, one would end up with $\mathrm{J}=\mathrm{J}$ and $\mathrm{S}=\mathrm{S}$ with no solutions. In such a situation, the spreadsheet will warn of "circular reference". A fixed number must be entered for $\mathrm{S}$ or the spreadsheet will not proceed. Therefore, $\mathrm{J}=\mathrm{S} / 2$ and $\mathrm{S}=6$ is the correct style for this variation. Now, $\mathrm{J}+\mathrm{S}$ will equal 9 as it did before in the original problem. Students do create circular logic and we felt it is apt to mention this common error.

Since creating charts using spreadsheets is fairly simple, students must be encouraged to create them as shown in Figures $6 \mathrm{a}$ and $6 \mathrm{~b}$. Such visual displays help reinforce the concepts and look at the problem in more ways. For example, it might occur to a student only after looking at the Pie chart that Juan has a third of the total number of apples. Students should be required to find the algebraic solution and only then set up the models into spreadsheets. They should be encouraged to find variations while working with spreadsheets. As problems become more involved, the value of creating charts and interpreting them will be considerable.

Figure 6a Pie Chart

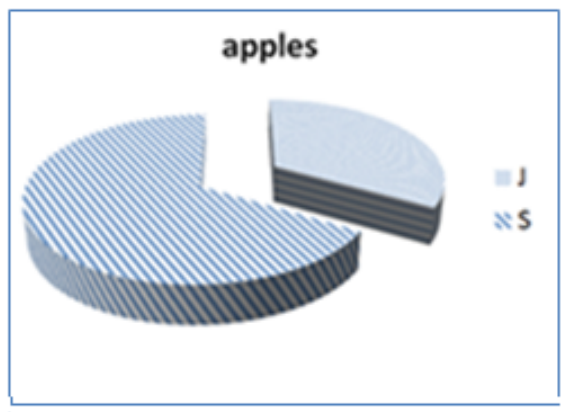

Figure $6 \mathrm{~b}$ Chart of apple quantities

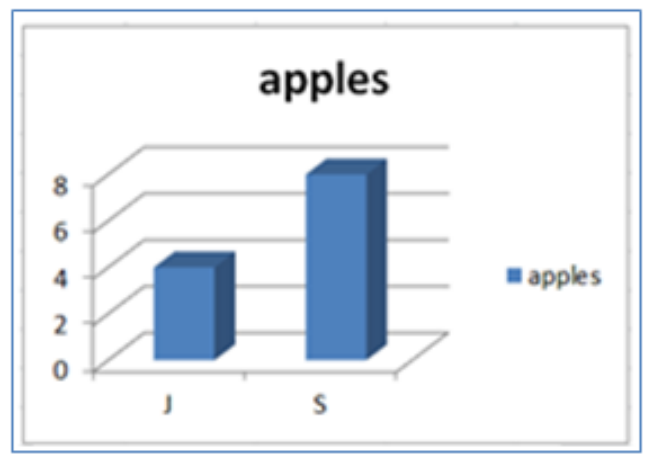

MORE EXAMPLES

\section{Problem 2}

Going back to Juan and Shana, suppose a friend, Fred, joins them. Juan has 4 apples and Shana has 8. Suppose that now the group of three have a total of 16 apples. How many apples did Fred bring to the group?

Algebraically, $\mathrm{J}+\mathrm{S}+\mathrm{F}=16 \rightarrow 4+8+\mathrm{F}=16 \rightarrow \mathrm{F}=4$. Figure 7 shows the spreadsheet solution. Cell $\mathrm{D} 2$ now has the formula that will find the sum of all apples. Upon pressing Enter after plugging in " $=\mathrm{J}+\mathrm{S}+\mathrm{F}$ " in cell D2, it will show 12 because we have no apples in Fred's cell. The student can enter " $=16-\mathrm{J}-\mathrm{S}$ " in cell B5 or could also use Goal Seek to figure out Fred's apples. The student could then be guided to alter the chart by including Fred and the student will see how easy it is to make new charts in the face of new circumstances. 
Figure 7 Fred joins the group

\begin{tabular}{|c|c|c|c|c|}
\hline & A & B & C & D \\
\hline 1 & J= Juan & S= Shana & F= Fred & Sum \\
\hline 2 & & apples & & $=J+S+F$ \\
\hline 3 & $J$ & 4 & & \\
\hline 4 & S & 8 & & \\
\hline 5 & F & & & \\
\hline C & & & & \\
\hline
\end{tabular}

\section{INTRODUCING COLUMNS}

Spreadsheets are excellent for developing mathematical models in columns. Columns can present data for components such as quantity and price and can be used for sequential steps performed simultaneously for each row. Rows can relate to different elements such as items for a birthday party or can relate to repetition of the same activity as might occur in a sales activity that is repeated day after day. Each day will have its own row.

\section{Problem 3: School project}

Students have volunteered to raise money as part of a local charity drive. Because work will be for charity, sales taxes will not apply. The charity plans to sell decorated three-ring notebooks. Students will use paint, paste, and magazine clippings to decorate the notebooks. What are the costs? What will be the profits? Notebooks cost $\$ 2.40$ each. Extras can be returned to the store. Colored paints, paste and magazines are being donated and hence free of cost. Sale price is $\$ 5.00$ per decorated notebook. The daily sales for four consecutive days are $85,84,67$, and 81 decorated notebooks respectively. What are the daily profits as well as total profits for this 4 day period?

The above information can be entered into a spreadsheet in an organized fashion as shown in Figure 8. It will also allow one to make a chart for profits. However, the student must be guided to solve it manually first as follows: Sale Price $=\$ 5.00$. Cost $=\$ 2.40 \rightarrow$ Unit Profit $=5 .-->0-2.40=\$ 2.60$. If they sell 85 units on Day 1 , total profits $=85$ $\mathrm{X} \$ 2.60=\$ 221$. The students can then calculate profits for the remaining days and also the total profits.

\section{Figure 8}

\begin{tabular}{|c|c|c|c|}
\hline$\Delta$ & A & B & C \\
\hline 1 & \multicolumn{3}{|c|}{ Decorated notebook project } \\
\hline 2 & & & \\
\hline 3 & notebook & $\$ 2.40$ & \\
\hline 4 & Price & $\$ 5.00$ & \\
\hline 5 & UnitProfit & & \\
\hline 6 & day & Number & Profit \\
\hline 7 & 1 & 85 & \\
\hline 8 & 2 & 84 & \\
\hline 9 & 3 & 67 & \\
\hline 10 & 4 & 81 & \\
\hline
\end{tabular}

For the sake of brevity, we will not get into specifics of obtaining Figure 9 along with the chart. We assume that elementary school teachers implementing Excel in the classroom would already know these basics. A variation to this problem could be if the teacher now challenges the students to assume that supplies were not free but cost a total of $\$ 28.50$ for the 4 day period. This could be an exercise for the student to show their organizational skills (by adding a label for supplies as well as for net profits) and also their modeling skills (by deducting cost of supplies 
from total profits). Such "what if?" questions hone their skills as well as reiterate important concepts. Another question left as an exercise could be to ask how many additional notebooks need to be sold if the goal of the charity drive is to make a profit of at least $\$ 1000$ (assuming there is no change in the cost of the supplies).

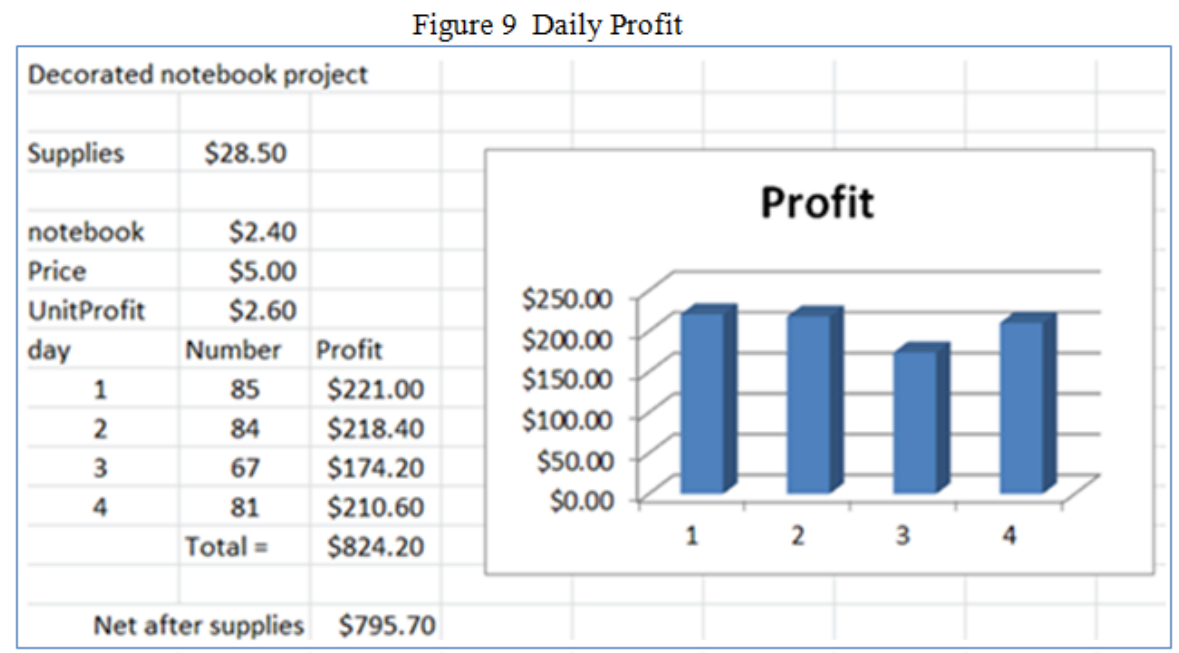

\section{ALGEBRAIC EQUATIONS}

The following examples are geared towards early high school students. Spreadsheets can be applied to algebraic problems although it should not replace the manual approach. Spreadsheets have several advantages: 1). Solutions will appear in clearly discernible steps. 2). There will be a permanent record of the computations performed. 3). Each solution acts as a template which can be used for solutions of similar problems. 4). Each solution can be extended to include other situations. 5). Often, numerical solutions for problems can be displayed graphically, offering improved conceptual understanding. 6). Spreadsheets offer their own report format and can be printed and distributed.

Consider $X^{2}+2 X-8=0$. Find the values for $X$. This can be solved algebraically by recognizing that $(X+4)(X-2)=$ 0 is equivalent to $X^{2}+2 X-8=0$. So $X=-4$ and $X=2$. There is a quadratic formula that supplies the answer if a student is unable to factor the polynomial. The quadratic function and the formula for finding the solution are given below as equations (1) and (2).

$$
\begin{aligned}
& a x^{2}+b x+c=0 \\
& x=\frac{-b \pm \sqrt{b^{2}-4 a c}}{2 a}
\end{aligned}
$$

\begin{tabular}{|c|c|c|c|c|c|c|c|}
\hline 4 & A & B & $\mathrm{C}$ & D & $\mathrm{E}$ & $\mathrm{F}$ & G \\
\hline 1 & \multicolumn{2}{|c|}{ Quadratic Form } & & \multicolumn{3}{|c|}{ Problem to be solved } & \\
\hline 2 & \multicolumn{2}{|c|}{$a x^{2}+b x+c=0$} & & $x^{2}+2 x-8$ & & & \\
\hline \multicolumn{8}{|c|}{3} \\
\hline 4 & & & & \multicolumn{2}{|c|}{ coefficients } & & \\
\hline 5 & \multicolumn{3}{|c|}{$x=\frac{-b \pm \sqrt{b^{2}-4 a c}}{2 a}$} & a & b & c & \\
\hline 6 & & & & 1 & 2 & -8 & \\
\hline 7 & \multicolumn{3}{|c|}{ Naming protocol has been used } & & & & \\
\hline 8 & \multicolumn{3}{|c|}{ for cells containing coefficients } & $X=$ & \multicolumn{3}{|c|}{$=\left(-b+S Q R T\left(b^{\wedge} 2-4^{*} a^{*} c \_\right)\right) /\left(2^{*} a\right)$} \\
\hline 9 & & & & $X=$ & \multicolumn{3}{|c|}{$=\left(-b-S Q R T\left(b^{\wedge} 2-4^{*} a^{*} c_{-}\right)\right) /\left(2^{*} a\right)$} \\
\hline
\end{tabular}

Figure 10 Showing formulas as you would enter them 
Figure 10 provides the formulas used after naming the cells D6, E6, F6 as a, b, and c_respectively. Note that Excel does not allow cell F6 to be named c and hence we chose "c_."

Plotting such functions can be useful. The solutions are where the plot crosses the X-axis. In order to create a plot of $a X^{2}+b X+C=0$, we need to create a column of $X$ values with a start value and an end value. To create the plot, first decide on a starting value and then on a step value. The step is the change between each successive value of $X$. Each new X value uses the value above it plus the step. In the case of Figure 11, the formula in B14 will be "=B13+B $\$ 12 "$ where the step value is in cell B12.

Figure 11 Plotting a Quadratic Function

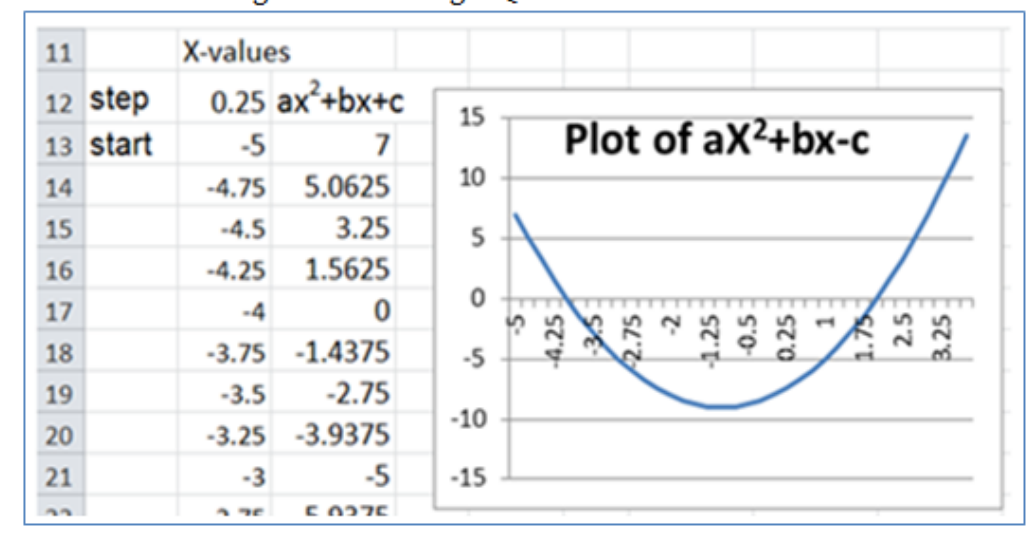

Start and step values can be changed as desired. The third column, headed by "aX $\mathrm{X}^{2}+\mathrm{bX}+\mathrm{c}$ " in Figure 11 shows the computed function value for each $\mathrm{X}$-value. The first formula in the column labeled "aX $\mathrm{X}^{2}+\mathrm{bX}+\mathrm{c}$ " is " $=\mathrm{a} * \mathrm{~B} 13^{\wedge} 2+\mathrm{b} * \mathrm{~B} 13+\mathrm{c}$." if the naming convention is used as $\mathrm{a}, \mathrm{b}$, and $\mathrm{c}_{-}$. If names are not used the formula will be "=D $\$ 6^{*} \mathrm{~B} 13^{\wedge} 2+\mathrm{E} \$ 6^{*} \mathrm{~B} 13+\mathrm{F} \$ 6 "$. The start value of $\mathrm{X}$ for this computation is in column $\mathrm{B}\left(2^{\text {nd }}\right.$ column) row 13 as seen in Figure 11. The \$ signs are used for absolute reference to the coefficient values located in D6, E6, and F6 of Figure 10. Note that Figures 10 and 11 are simply shown as separate figures for convenience. In reality, everything is done on a single spreadsheet. Now to create a column of function values, simply copy this formula down the column as far as needed. This graphical approach is neither simple nor intuitive. However, the process will not be difficult for students who start using spreadsheets at a young age and have progressed since then. Note that this graphic approach can be extended to higher order equations too and offers a solution where factoring is difficult.

\section{CONCLUSION}

We propose an introduction to "Computational Thinking" at an early stage in grade school. We agree with current literature about the necessity of computational thinking for workforce in today's world and that it should be taught in tandem with other core areas like reading, writing and mathematics in grade school. We provide several examples involving basic algebra to argue the importance of computational thinking where use of spreadsheets go beyond just solving a problem. In other words, a student can look at different scenarios as well as ask "what if" kind of questions. This would go a long way in preparing students for the workplace of tomorrow.

\section{AUTHOR BIOGRAPHIES}

John Sanford is an Emeritus Professor of Information Systems at Philadelphia University. He holds a Ph.D. in Engineering from Yale University. His teaching interests are in the areas of MIS, Operations Management and Statistics. His research interests include information systems, Data Analysis, and data analysis with Fuzzy Systems. His recent publications are in The International Journal of Teaching and Case Studies and American Journal of Business Education.

Jaideep Naidu is an Associate Professor of Operations Management and Management Science at the School of Business Administration, Philadelphia University. He holds a Ph.D. in Operations Management from The University 
of Mississippi. His research interests center on machine scheduling problems and higher education. Among other journals, his work has appeared in Journal of the Operational Research Society, Omega - The International Journal of Management Science, International Journal of Operations and Quantitative Management, and American Journal of Business Education.

\section{REFERENCES}

Best, M.L. (2014). Global Computing: Thinking outside the Continent. Communications of the ACM, 57 (4), 27 - 29.

Carnegie Mellon (2014). Carnegie Mellon Center for Computational thinking, http://www.cs.cmu.edu/ CompThink/ cited $8 / 12 / 2014$.

Monroe, D. (2014). A New Type of Mathematics? Communications of the ACM , 57 (2), 13 - 15.

Google (2014). Lesson Plans for Teachers. http://www.google.com/edu/teachers/lesson-plan-search.html cited 8/12/2014.

IBM (2011). IBM's Watson competed on the NBC television quiz show "Jeopardy" in 2011.

Sanford J.F. (2013). Core concepts of computational thinking. Intl. Journal of Teaching and Case Studies, 4(1), 1-12.

Wilensky, U., Brady, C. E. \& Horn, M.S. (2014). Fostering Computational Literacy in Science Classrooms. Communications of the $A C M, 57$ (8), $24-28$.

Wing, J. M. (2006). Computational Thinking. Communications of the ACM, 49 (3), 33 - 35. 
NOTES 